\title{
THE INFRARED SENSOR SUITE FOR SNOWEX 2017
}

\author{
D.K Hall ${ }^{1}$, C.C. Chickadel ${ }^{2}$, C.J. Crawford ${ }^{3}$, E.L. DeMarco ${ }^{4}$, D.E. Jennings ${ }^{5}$, M.D. Jhabvala ${ }^{5}$, E.J. Kim ${ }^{5}$, \\ J.D. Lundquist ${ }^{2}$, A.W. Lunsford ${ }^{6}$ \\ ${ }^{1}$ Michigan State University, East Lansing, MI 48824 \\ ${ }^{2}$ University of Washington, Seattle, WA 98195 \\ ${ }^{3}$ University of Maryland, College Park, MD 20740 \\ ${ }^{4}$ ATA Aerospace, Greenbelt, MD 20770 \\ ${ }^{5}$ NASA / Goddard Space Flight Center, Greenbelt, MD 20771 \\ ${ }^{6}$ Catholic University of America, Washington, D.C. 20064
}

\begin{abstract}
SnowEx is a winter airborne and field campaign designed to measure snow-water equivalent in forested landscapes. A major focus of Year 1 (2016-17) of NASA's SnowEx campaign will be an extensive field program involving dozens of participants from U.S. government agencies and from many universities and institutions, both domestic and foreign. Along with other instruments, two infrared (IR) sensors will be flown on a Naval Research Laboratory P-3 aircraft. Surface temperature is a critical input to hydrologic models and will be measured during the SnowEx mission. A Quantum Well Infrared Photodetector (QWIP) IR imaging camera system will be flown along with a KT-15 remote thermometer to aid in the calibration of the IR image data. Together, these instruments will measure surface temperature of snow and ice targets to an expected accuracy of $<1^{\circ} \mathrm{C}$.
\end{abstract}

Index Terms - Infrared, SnowEx, Remote Sensing

\section{INTRODUCTION}

While snow-covered area has been measured for 50 years using satellite data, accurate measurement of snow-water equivalent (SWE) globally from space has been elusive. At present, SWE can only be measured reliably in the field.

Snowmelt is an important source of freshwater for billions of people worldwide, and the associated hazards that may be related to rapid snowmelt (flooding) or too little snowmelt (drought) can take an economic and human toll. Thus the quantity of snow, not just the areal extent of snow cover, is of great interest.

SnowEx is a 5-year airborne snow project designed specifically to address the need to measure global SWE from space. SnowEx activities will advance our ability to estimate global SWE and provide experience toward defining a snow space mission concept.

Though a great deal of progress has been made toward estimating SWE using space-borne microwave sensors and lidar, there is much work to be done to increase the coverage and accuracy of measuring SWE from space in a variety of landscapes. Accurate measurement of infrared (IR) surface temperature is needed to calculate the energy balance in distributed snow models $[1,2]$. Surface temperature controls the initiation of snowmelt [3] and is thus critical for inclusion in hydrology models. 
In the 2016-17 winter, the SnowEx project overarching objective is to measure SWE in a gradient of forest-cover densities to determine the sensitivities of various instruments for measuring SWE. There will be several aircraft flying with multiple sensors. Two IR sensors will be flown on board a Naval Research Lab (NRL) P-3 aircraft. These are a Quantum Well Infrared Photodetector (QWIP) infrared imaging camera system manufactured by QmagiQ and operated by NASA / Goddard Space Flight Center, and the University of Washington's KT-15 82D infrared thermometer. The KT-15 is a nadir-pointing sensor that will be cross calibrated with the QWIP IR camera. Together these instruments will measure surface temperature of snow and ice targets to an expected accuracy of $<1^{\circ} \mathrm{C}$ over snow sites in Colorado and snow and lake ice sites in Michigan in February of 2017.

\section{IR INSTRUMENTS ON THE SNOWEX MISSION IN YEAR 1}

The IR sensors will be flown on the P-3 along with a video camera and active- and passivemicrowave sensors, as well as a cloud-absorption radiometer.

The QWIP camera system is essentially an infrared version of a video camcorder that is capable of detecting temperature variations of $\sim 0.02^{\circ} \mathrm{C}$. The QWIP camera records infrared images of target sources in the 8-10 $\mu \mathrm{m}$ band at a frame rate of $60 \mathrm{~Hz}$. It has a field-of-view (FOV) of 11x9 degrees and a $~ 1.8 \mathrm{~m}$ pixel ground resolution at $10000 \mathrm{ft}$ altitude [4,5].

The camera will collect thermal images of snow fields from various altitudes under the control of a trained operator. The data volume depends on the frame rate and the actual flight paths and altitudes flown during the observations. The frame rate of the IR camera is adjusted to maintain overlapping imagery, and can be either $1 \mathrm{~Hz}$, or $60 \mathrm{~Hz}$. The maximum expected total data volume estimate for all SnowEx overflights in February of 2017 is about 200 GB.

Thermal imaging will be accomplished in conjunction with KT-15 temperature measurements. The KT-15 will overlap a subset of the IR camera FOV, providing temperature calibration for the IR camera that will be extrapolated to the entire IR image.

The KT-15 82D is a radiometer with sensitivity in the $8-14 \mu \mathrm{m}$ range, $\mathrm{a}-50^{\circ} \mathrm{C}$ to $50^{\circ} \mathrm{C}$ response, $\sim 2^{\circ}$ FOV ( 100m footprint at $10000 \mathrm{ft}$ AGL), and a resolution of $0.4-0.6 \mathrm{~K}$ at $10 \mathrm{~Hz}$ sampling (0.5 0.8K@20Hz). The output is an ASCII file of temperature and time and will be contemporaneous with the QWIP data for calibration of that imagery.

\section{CALIBRATION AND VALIDATION OF THE IR SENSORS}

The QWIP IR camera has been operated in the lab in flight configuration and has previously been flown successfully [6]. It has been tested over a range of temperatures from $-28^{\circ} \mathrm{C}$ to $-8^{\circ} \mathrm{C}$, and using a "slush bath" at $0^{\circ} \mathrm{C}$. Results of lab testing of the IR camera and the KT-15 showed that the QWIP camera is stable to within $1^{\circ} \mathrm{C}$. Additional laboratory testing and a flyover of ground calibration / validation targets will be performed prior to deployment of the P-3 aircraft to Colorado for the main snow experiment.

In-situ measurements of air and surface temperature will be acquired in the field to compare with the QWIP and KT-15 measurements. Data from the IR instruments will also be used to evaluate the accuracy of coincident satellite-derived IR measurements acquired from the Moderate Resolution Imaging Spectroradiometer (MODIS) on both the Terra and Aqua satellites [7], the Visible Infrared Imaging Radiometer Suite (VIIRS) and the Landsat-8 Thermal Infrared Sensor (TIRS), when sky conditions permit. 


\section{CONCLUSION}

The combination of the QWIP IR camera and the KT-15 nadir-viewing IR sensor will provide accurate maps of surface temperature over snow and ice targets in Colorado and Michigan in the first year of the SnowEx mission. The accuracy of the IR aircraft measurements should be better than $1^{\circ} \mathrm{C}$, which is suitable for use in modeling efforts to calculate snowmelt and surface energy balance.
Using Oblique Thermal Imaging,” 1st International Planetary Cave Research Workshop, Carlsbad, NM, October, 2011.

[7] D. K. Hall, S. V. Nghiem, I. G. Rigor and J. A. Miller, "Uncertainties of temperature measurements on snow-covered land and sea ice from in-situ and MODIS data during BROMEX," J. Appl. Meteor. Climatol, doi:10.1175/JAMC-D14-0175.1, 2015.

\section{REFERENCES}

[1] M. S. Raleigh, C. C. Landry, M. Hayashi, W. L. Quinton, and J. D. Lundquist, "Standard air temperature and humidity approximate snow surface temperature: new possibilities for snow model calibration," Water Resources Research, 49, doi:10.1002/2013WR013958, 2013.

[2] J. D. Lundquist, Wayand, N. E., Massmann, A., Clark, M. P., Lott, F. and Cristea, N. C., "Diagnosis of insidious data disasters," Water Resources Research, 51(4), 2498-2514, doi:10.1002/2014WR016585, 2015.

[3] K. E. Lapo, L. M. Hinkelman, M. S. Raleigh, and J. D. Lundquist, "Impact of errors in the downwelling irradiances on simulations of snow water equivalent, snow surface temperature, and the snow energy balance," Water Resources Research, 51(3), 1649-1670, doi:10.1002/2014WR016259, 2015.

[4] M. Jhabvala, D. Reuter, K. Choi, C. Jhabvala and M. Sundaram, "QWIP-based thermal infrared sensor for the Landsat Data Continuity Mission," Infrared Physics and Technology, 2009

[5] M. Jhabvala and K. Choi, "Evolution of QWIP focal plane development at the NASA/Goddard Space Flight Center," Proc. of SPIE, San Francisco, January 2012.

[6] N. Titus, J. J. Wynne, M. D. Jhabvala, G. E. Cushing, P. Shu, N. A. Cabrol, "Cave Detection 